EMBRYARIDDLE
Aeronautical University

SCHOLARLY COMMONS

\section{International Journal of Aviation,} Aeronautics, and Aerospace

\title{
Design and Simulation of Regional Navigation Constellation with Optimized Mean DOP based on Hybrid GEO and IGSO Satellites
}

\author{
firooz keyvani \\ Iran University of Science \& Technology, firooz.keyvani@gmail.com \\ Seyed Hosein Torabi \\ K.N.Toosi University of Technology, Tehran, Iran, htorabi@mail.kntu.ac.ir
}

Follow this and additional works at: https://commons.erau.edu/ijaaa

Part of the Navigation, Guidance, Control and Dynamics Commons

\section{Scholarly Commons Citation \\ keyvani, f., \& Torabi, S. (2019). Design and Simulation of Regional Navigation Constellation with Optimized Mean DOP based on Hybrid GEO and IGSO Satellites. International Journal of Aviation, Aeronautics, and Aerospace, 6(2). https://doi.org/10.15394/ijaaa.2019.1307}

This Article is brought to you for free and open access by the Journals at Scholarly Commons. It has been accepted for inclusion in International Journal of Aviation, Aeronautics, and Aerospace by an authorized administrator of Scholarly Commons. For more information, please contact commons@erau.edu. 


\section{Introduction}

After launching global coverage satellite constellation, many countries began to think about setting up regional navigation constellations. Navigation is a science guided by the taking of a device or person to go from a place to another place. Each of us has experienced some kind of navigation in our daily lives. Signals transmitted from one or more radio navigation devices aid a person or user to calculate his location. Some radio navigation tools also have the ability to calculate the speed and time spent. The receiver performs essential calculations (such as distance, direction, and approximate time elapsed) until it reaches the destination. There are several types of radio navigation tools that can be categorized into two types of tools: on the ground tools and space tools. The spatial navigation section is the focus of this paper.

Renault (1998) discussed the characteristics of systems consisting of Geostationary Orbit (GEO) and Inclined Geosynchronous Orbit (IGSO) satellites for regional navigation purposes. He emphasized that GEO-based constellation are the best solution for regional coverage. In this paper, two constellations, one based on GEO satellites, and another based on IGSO satellites, were investigated and the vertical dilution of precision (VDOP) and horizontal dilution of precision (HDOP) were compared:

-The highest accuracy in determining the horizontal position is achieved by satellites at low angles and at high scattering angles (appropriate azimuth angles).

-The highest accuracy in determining the vertical position is achieved by a combination of satellites at high and low angles.

Eventually, he concluded that a constellation consisting of three GEO satellites and three IGSO satellites in three different orbits is an acceptable constellation for navigating in areas with a mean latitude. Also, the presence of GEO satellites in the constellation helps to increase the level of coverage and reduce VDOP. Constellations based on GEO satellites have a lower vertical positioning error than IGSO satellites do, but the opposite is true for horizontal positioning errors (HDOPs) (Renault, 1998).

Montenbruck, Steigenberger, Hugentobler, Teunissen, and Nakamura (2013) emphasized the use of GEO satellites in their suggested constellation. For regional coverage, they suggest 4 GEO satellites, 3 IGSO satellites with 2 MEO satellites, 2 satellites in orbit of tundra, and 3 satellites in HEO. They carried out their research by considering components such as the number of GEO satellites, positioning, and their distance from each other as well as features of IGSO satellites.

Angrisano, Pacifico, and Vultaggio (2008) have researched several GPS-based navigation systems, with the aim of covering the continent of Europe. Their main goal is to create an appropriate cover and GDOP reduction in parts of Europe in which the height of constructandions of the Earth are high and GPS alone is not efficient. They simulated 4 constellations. The first one is the same as the GPS. The second constellation is comprised of GPS and 3 GEO satellites, called EGNOS, which currently covers the continent of 
Europe. The third one combined GPS and a constellation similar to QZSS, which is again designed to cover the continent of Europe. Finally, the GPS + EGNOS + QZSS constellation was reviewed. The problem was optimized in 3 modes with three elevation angles: 15, 30, and 40 degrees. Results are provided based on the number of available satellites and percentage time in which DOP is less than 4.5 for each constellation and is compared with the results of other constellations.

The authors of this paper have endeavored to reach the regional constellation with optimized Dilution of Precision (DOP) and $100 \%$ Availability. To check the coverage in the area, three points have been considered. DOP is a term used in satellite navigation and geometric engineering to specify the additional multiplicative effect of navigation satellite geometry on positional measurement precision, and it is defined when at least four satellites are in view. With this process, cost function is defined which focuses on creating 100\% coverage and minimize the DOP. Optimizations were performed for the different layouts of the satellites. The entire process was done using the genetic algorithm. Given that the calculations of DOP are optimized at a particular moment (the best layout at $\mathrm{t}=0$ ), in this study, the Mean DOP is introduced which expresses the average of the DOP in a specified period.

\section{Regional Navigation Constellations}

\section{Beidou}

The BeiDou is a Chinese satellite navigation system. It consists of two separate satellite constellations. The first BeiDou system, called the BeiDou-1, consists of three satellites which mainly for users in China and neighboring regions. Beidou-1 was decommissioned at the end of 2012. The second generation of the system, called the COMPASS, or BeiDou-2, became operational in China in December 2011 with a partial constellation of 10 satellites in orbit. Since December 2012, it has been offering services to customers in the Asia-Pacific region (Sun, Liu, Zhu, \& Men, 2012). In 2015, China started the build-up of the third generation BeiDou system (BeiDou-3) in the global coverage constellation. BeiDou-3 will eventually consist of 35 satellites and is expected to provide global services upon completion in 2020 (Harshada, Shahade, \& Badnore, 2015).

\section{IRNSS}

The Indian Regional Navigation Satellite System (IRNSS) is an autonomous regional satellite navigation system that provides accurate realtime positioning and timing services. It covers India and a region extending $1,500 \mathrm{~km}$ around it, with plans for further extension. The system at present consists of a constellation of seven satellites. Three of the seven satellites are located in GEO at $32.5^{\circ}$ East, $83^{\circ}$ East, and $131.5^{\circ}$ East longitude. The 
remaining four satellites are in IGSO. Two of them cross the equator at $55^{\circ}$ East and two at $111.75^{\circ}$ East (Ai et al., 2008; Saikiran \& Vikram, 2013).

\section{CAPS}

CAPS (Chinese Area Positioning System) is a "passive" one-way system similar to most navigation systems. But CAPS is also different from all the other navigation satellite systems in that the navigation messages are generated on the ground and uploaded to the communication satellites so receivers are only "listeners" (Ai et al., 2009).

The CAPS constellation consists of commercial GEO and IGSO communication satellites. These spacecraft are not traditional navigation satellites and all the navigation-related facilities are all located on the ground. This system has three major advantages:

-The operation does not require the launch of specific navigation satellites, so the cost is much lower.

-The system can use a larger but more accurate and reliable atomic clock and maintenance is obviously much easier.

-New applications can be considered for this system that are not inherent in other navigation satellite systems (Ai, 2009; Cong, Abidat, \& Tan, 2006). See Table 1 for a comparison of features. 
Table 1

Satellite Constellations Comparison

\begin{tabular}{|c|c|}
\hline Feature & Description \\
\hline Cost & $\begin{array}{l}\text { CAPS is much cheaper than other navigation satellite systems, for } \\
\text { two reasons: the system uses GEO communication satellites, } \\
\text { especially retired ones and generates the navigation } \\
\text { messages on the ground. }\end{array}$ \\
\hline Coverage & $\begin{array}{l}\text { CAPS was developed for China, but a much larger Asian-Oceania } \\
\text { area can benefit from it, especially South East Asia and part of } \\
\text { Australia. IRNSS is for India and Regional (up to } 1,600 \mathrm{~km} \text { from } \\
\text { borders) but Beidou- } 2 \text { has global coverage. }\end{array}$ \\
\hline Usage & $\begin{array}{l}\text { Because the CAPS spacecraft are communication satellites, they } \\
\text { can be used not only for navigation but also for navigation-related } \\
\text { communications or redeployed primarily for general } \\
\text { communications at any time but Beidou and IRNSS are } \\
\text { navigation only. }\end{array}$ \\
\hline \multirow{2}{*}{$\begin{array}{l}\text { Frequency } \\
\text { band }\end{array}$} & $\begin{array}{l}\text { C-band is used for the data link in CAPS, making interoperability } \\
\text { more complicated than for systems operating at L-band. Beidou } \\
\text { and IRNSS use L-band. }\end{array}$ \\
\hline & $\begin{array}{l}\text { CAPS system faces the possibility of same-frequency interference } \\
\text { from other communication satellites. To solve this problem will } \\
\text { require the collaboration of many organizations. }\end{array}$ \\
\hline Reliability & $\begin{array}{l}\text { In CAPS constellation Because the satellite is only a transponder, } \\
\text { the navigation signal relies on the ground station. If anything } \\
\text { happens to the ground station or the uplink, the satellite loses its } \\
\text { navigation function. Compared with the other navigation satellite } \\
\text { systems like Beidou and IRNSS, therefore, CAPS is more } \\
\text { vulnerable }\end{array}$ \\
\hline DOP & $\begin{array}{l}\text { Generally, the DOP of CAPS is not as good as that of GNSS } \\
\text { systems. }\end{array}$ \\
\hline Accura & $\begin{array}{l}\text { CAPS Positioning, velocity, and time (PVT) accuracy is not as } \\
\text { good as for GNSS systems. }\end{array}$ \\
\hline
\end{tabular}

\section{DOP}

Dilution of Precision (DOP) is a factor that describes the effect of geometry on the relationship between measurement error and position determination error. It is used to provide an indication of the quality of the solution. DOP can be expressed as a number of separate measurements:

HDOP - horizontal dilution of precision

VDOP - vertical dilution of precision

PDOP - position dilution of precision

TDOP - time dilution of precision 
As the first step in computing DOP, consider the unit vectors from the receiver to satellite $\mathrm{i}$ :

$$
\left(\frac{\left(x_{i}-x\right)}{R_{i}}, \frac{\left(y_{i}-y\right)}{R_{i}}, \frac{\left(z_{i}-z\right)}{R_{i}}\right)
$$

Where

$$
\mathrm{R}_{\mathrm{i}}=\sqrt{\left(\mathrm{x}_{\mathrm{i}}-\mathrm{x}\right)^{2}+\left(\mathrm{y}_{\mathrm{i}}-\mathrm{y}\right)^{2}+\left(\mathrm{z}_{\mathrm{i}}-\mathrm{z}\right)^{2}}
$$

and where $\mathrm{x}, \mathrm{y}$, and $\mathrm{z}$ denote the position of the $\mathrm{r}$ ceiver and $\boldsymbol{x}_{\boldsymbol{i}}, \boldsymbol{y}_{\boldsymbol{i}}$ and $\boldsymbol{z}_{\boldsymbol{i}}$ denote the position of satellite i. Formulate the matrix, A, which is (for 4 range measurement):

$$
A=\left[\begin{array}{cccc}
\frac{\left(x_{1}-x\right)}{R_{1}} & \frac{\left(y_{1}-y\right)}{R_{1}} & \frac{\left(z_{1}-z\right)}{R_{1}} & -1 \\
\frac{\left(x_{2}-x\right)}{R_{2}} & \frac{\left(y_{2}-y\right)}{R_{2}} & \frac{\left(z_{2}-z\right)}{R_{2}} & -1 \\
\frac{\left(x_{3}-x\right)}{R_{3}} & \frac{\left(y_{3}-y\right)}{R_{3}} & \frac{\left(z_{3}-z\right)}{R_{3}} & -1 \\
\frac{\left(x_{4}-x\right)}{R_{4}} & \frac{\left(y_{4}-y\right)}{R_{4}} & \frac{\left(z_{4}-z\right)}{R_{4}} & -1
\end{array}\right]
$$

The first three elements of each row of A are the components of a unit vector from the receiver to the indicated satellite. If the elements in the fourth column are c which denotes the speed of light then the $\sigma_{t}$ factor (time dilution) is always 1 . If the elements in the fourth column are -1 then the $\sigma_{t}$ factor is calculated properly. Formulate the matrix, $\mathrm{Q}$, as:

$$
Q=\left(A^{T} A\right)^{-1}
$$

The Q matrix acts as a covariance matrix and can be used to determine the values of the PDOP, GDOP (geometric dilution of precision), and etc. parameters.

$$
\mathrm{Q}=\left[\begin{array}{cccc}
\sigma_{\mathrm{x}}^{2} & \sigma_{\mathrm{xy}} & \sigma_{\mathrm{xz}} & \sigma_{\mathrm{xt}} \\
\sigma_{\mathrm{xy}} & \sigma_{\mathrm{y}}^{2} & \sigma_{\mathrm{yz}} & \sigma_{\mathrm{yt}} \\
\sigma_{\mathrm{xz}} & \sigma_{\mathrm{yz}} & \sigma_{\mathrm{z}}^{2} & \sigma_{\mathrm{zt}} \\
\sigma_{\mathrm{xt}} & \sigma_{\mathrm{yt}} & \sigma_{\mathrm{zt}} & \sigma_{\mathrm{t}}^{2}
\end{array}\right]
$$

PDOP, GDOP, and TDOP are given by: 
$\mathrm{PDOP}=\sqrt{\sigma_{\mathrm{x}}^{2}+\sigma_{\mathrm{y}}^{2}+\sigma_{\mathrm{z}}^{2}}$

$\mathrm{TDOP}=\sqrt{\sigma_{\mathrm{t}}^{2}}$

$\mathrm{GDOP}=\sqrt{\mathrm{PDOP}^{2}+\mathrm{TDOP}^{2}}$

In this relationship, the GDOP geometric accuracy coefficient (DOP), PDOP position accuracy factor and TDOP are the precision coefficients of time. If the DOP factors are too large you cannot do any position determination, in fact, the matrix Q is singular (Mao \& Sun, 2006).

The value of the DOP parameter determined at a certain moment, so to design a satellite constellation which has an optimal DOP and availability through the day and night, Mean DOP is defined and is selected as a cost function to be optimization.

Mean DOP $=\frac{\sum_{\mathrm{i}=0}^{\mathrm{N}-1} \mathrm{DOP}_{\mathrm{i}}}{\mathrm{N}}$

\section{Design of a Regional Navigation Satellite System}

In order to simulate and analyze the DOP parameter, the MATLAB and STK software were used independently. Assumptions considered under this topic are as follows:

-A permanent navigation constellation for an area. The number of satellites in this constellation in the first step is 6 which can be a combination of IGSO satellites and GEO; furthermore, seven satellites are also used. These two values are selected based on previous experiences. Selecting a large number of satellites has financial constraints and fewer than 6 satellites causes availability loss and as a result the DOP will be affected (Mao \& Sun, 2006).

According to the Table 2, the Omega and nu parameters are unknown and the rest of the parameters are Specified on this issue. Semi-major axis, Eccentricity and Argument of perigee quantities are determined by the choice of GEO and IGSO satellites, the value of inclination parameter is also determined with the ability of the launcher and the position of the launch location. 
Table 2

\begin{tabular}{|c|c|c|}
\hline $\mathrm{a}$ & Semi-maior axic & Snecified \\
\hline & & \\
\hline ecc & Eccentricity & Specified \\
\hline inc & $\begin{array}{l}\text { The inclination of } \\
\text { orbit in radians }\end{array}$ & Specified \\
\hline Omega & $\begin{array}{l}\text { The right ascension } \\
\text { of ascending node } \\
\text { in radians }\end{array}$ & Unknown \\
\hline $\mathrm{W}$ & $\begin{array}{l}\text { Argument of } \\
\text { perigee in radians }\end{array}$ & Specified \\
\hline $\mathrm{nu}$ & $\begin{array}{l}\text { True anomaly in } \\
\text { radians }\end{array}$ & Unknown \\
\hline
\end{tabular}

Given the optimization by the genetic algorithm, it is necessary to determine the range for unknown parameters. Hence, for two unknown parameters, certain boundaries have been selected. For the nu parameter, the range is 0 to 360 degrees, which includes the whole range and for the Longitude of ascending node (Omega) parameter, it should be selected in such a way the all of selected stations are in line of sight of GEO satellites (latitude $=0 \mathrm{deg}$ ).

The steps taken to optimize the design of the navigation constellation are as follows:

-Determine the number of satellites

-Determine the orbital parameters

-Select the appropriate range for the unknown parameters

-Optimization by Genetic Algorithm to Minimize DOP

The final step includes the following functions:

-First Function: Converts orbital parameters to the ECI coordinate system

-Second Function: Converts the parameters of $\mathrm{X}, \mathrm{Y}, \mathrm{Z}$ to the ECI to $\mathrm{ECEF}$ (MERNSS)

-Function III: DOP calculation

-Design of Middle East Regional Navigation Satellite System

In this article, a regional navigation constellation is considered as an example. This constellation is considered to be in the Middle East and three stations in Tehran, Beirut, and Kabul are selected as the three points of this 
region. The Longitude of ascending node (Omega) parameter is considered to be from -4 to 97 degrees, considering the following conditions:

-Ground station viewing range in Tehran: -27 to $119 \mathrm{deg}$.

-Ground station viewing range in Beirut: -44 to $102 \mathrm{deg}$.

-Ground station viewing range in Kabul: -9 to $137 \mathrm{deg}$.

-Considering the 5-degree cutoff angle for ground stations: The range of Longitude of ascending node is -4 to $97 \mathrm{deg}$.

-Generally, a satellite is considered low elevation if it is between 0 and 15 degrees above the horizon. Use of satellites below 5 degrees is not recommended (Mao \& Sun, 2006).

-Cutoff angle is the minimum acceptable satellite elevation angle (above the horizon) to avoid blockage of line-of-sight, multipath errors, or too high Tropospheric or Ionospheric Delay values. May be preset in the receiver, or applied during data post-processing. For navigation receivers, typically a cutoff angle of $5^{\circ}$ is used (Mao \& Sun, 2006).

-Regional Navigation constellations have usually 6 or 7 satellites so they cannot be placed in MEO, because in MEO, the satellite's orbital velocity is different than the earth's rotation speed. A MEO satellite will not hover over specific region all the time, they will hover over entire earth.

-In GEO and GSO orbits, the orbital velocity of a satellite is same as the rotation speed of earth so a Regional constellation satellite placed in these orbits will always hover over specific region (Capderou, 2006). Table 3 shows the comparison of GEO and MEO. 
Table 3

GEO and MEO Comparison

\begin{tabular}{|c|c|c|}
\hline Satellite feature & GEO satellite & MEO satellite \\
\hline Full form & Geostationary Earth Orbit satellite & $\begin{array}{l}\text { Medium Earth } \\
\text { Orbit Satellite }\end{array}$ \\
\hline Orbital period & 24 hours & 2 to 8 hours \\
\hline Satellite life & Long & Medium \\
\hline $\begin{array}{l}\text { Propagation } \\
\text { loss }\end{array}$ & Highest & high \\
\hline $\begin{array}{l}\text { Number of } \\
\text { satellites for } \\
\text { Regional } \\
\text { Navigation } \\
\text { Constellation } \\
\end{array}$ & 6 or 7 & more than 24 \\
\hline $\begin{array}{l}\text { Number of } \\
\text { satellites for } \\
\text { full coverage }\end{array}$ & 3 & 8 to 20 \\
\hline \multirow{4}{*}{ Advantages } & $\begin{array}{l}\text { Covers large geographical area, Only } \\
\text { three GEO satellites are needed to } \\
\text { cover earth. }\end{array}$ & $\begin{array}{l}\text { With MEO } \\
\text { satellite lesser } \\
\text { number } \\
\text { satellite network } \\
\text { required } \\
\text { compared to } \\
\text { LEO satellite to } \\
\text { cover the area. }\end{array}$ \\
\hline & $\begin{array}{l}\text { Visible for } 24 \text { hours from fixed } \\
\text { location on earth }\end{array}$ & $\begin{array}{l}\text { Lesser time } \\
\text { delay in the } \\
\text { signal compared } \\
\text { to GEO satellite }\end{array}$ \\
\hline & $\begin{array}{l}\text { GEO and IGSO satellites in very } \\
\text { useful for Regional navigation } \\
\text { constellation. Because of cost and } \\
\text { ability to use retired satellite }\end{array}$ & $\begin{array}{l}\text { For Global } \\
\text { Navigation } \\
\text { constellation, } \\
\text { MEO satellites } \\
\text { are the best } \\
\text { option (like } \\
\text { GPS) }\end{array}$ \\
\hline & $\begin{array}{l}\text { Ideal for satellite broadcast and } \\
\text { multipoint communication }\end{array}$ & \\
\hline Disadvantages & $\begin{array}{l}\text { Considerable time delay in the signal, } \\
\text { which is not favorable for point to } \\
\text { point communication. }\end{array}$ & $\begin{array}{l}\text { Weaker signal } \\
\text { compared to } \\
\text { LEO since it is } \\
\text { higher orbit than } \\
\text { LEO }\end{array}$ \\
\hline
\end{tabular}




\begin{tabular}{|l|l|l|}
\hline & $\begin{array}{l}\text { Since it is above the equator, it faces } \\
\text { difficulty in broadcasting near polar } \\
\text { region. }\end{array}$ & $\begin{array}{l}\text { Visible for only } \\
\text { a hours from } \\
\text { location on earth. }\end{array}$ \\
\hline
\end{tabular}

Cost can be a significant factor in the Regional navigation constellation final solution, but the cost of launching is not evaluated in this article because satellites launch site are unknown and there is also the possibility of using retired GEO satellites. The designed constellations in this research are a combination of IGSO and GEO layouts. Various layouts are as follows:

-Six IGSO satellites

-Five IGSO satellites and a GEO satellite

-Four IGSO satellites and two GEO satellites

-Three IGSO satellites and three GEO satellites

-Two IGSO satellites and four GEO satellites

-Four IGSO satellites and three GEO satellites

-Three IGSO satellites and four GEO satellites

Of the 7 states listed, five modes have been simulated and optimized using six satellites and two modes using seven satellites. Ground stations are considered at the three points of Kabul (east), Tehran (center), and Beirut (west). In order to increase the accuracy of the calculations, the minimum angle of the receivers or the Cutoff angle is also considered in the calculations.

Consequently, the outer angle between the two vectors, the vector of the station location, and the vector between the station and the satellite are considered, and if this angle is greater than 85 degrees, it means that the cutoff angle is lower than 5 degrees. As a result, we exclude these satellites from the calculations. It should be noted in this case that if the number of satellites is less than 4, we consider the fixed value of 1000 for DOP because otherwise in these moments, DOP will have an undefined value which causes error in the final output. In Tables 4, 5, and 6, the DOP and Availability of three stations have been shown. 
Table 4

Availability and Mean DOP in Tehran Station

\begin{tabular}{|l|ll|l|l|l|l|}
\hline No. & Layout & Availability & GDOP & PDOP & HDOP \\
\hline 1 & $6 *$ IGSO & $82 \%$ & 7.78 & 6.93 & 4.65 \\
\hline 2 & $\begin{array}{l}5 * \text { IGSO \& } \\
1 * \text { GEO }\end{array}$ & $86 \%$ & 4.16 & 3.5 & 1.89 \\
\hline 3 & $\begin{array}{l}4 * \text { GGO \& } \\
2 * \text { GEO }\end{array}$ & $100 \%$ & 4.75 & 4.12 & 2.06 \\
\hline 4 & $3 *$ GEO \& & $100 \%$ & 3.81 & 3.39 & 1.77 \\
\hline 5 & $\begin{array}{l}2 * \text { IGSO \& } \\
4 * \text { GEO }\end{array}$ & $100 \%$ & 4.58 & 4.19 & 2.69 \\
\hline 6 & $\begin{array}{l}3 * \text { IGSO \& } \\
4 * \text { GEO }\end{array}$ & $100 \%$ & 3.67 & 3.27 & 1.66 \\
\hline 7 & $\begin{array}{l}4 * \text { GEO \& } \\
3\end{array}$ & $100 \%$ & 3.58 & 3.14 & 1.57 \\
\hline
\end{tabular}

Table 5

Availability and Mean DOP in Beirut Station

\begin{tabular}{|c|c|c|c|c|c|}
\hline No. & Layout & Availability & GDOP & PDOP & HDOP \\
\hline 1 & 6*IGSO & $83 \%$ & 5.86 & 5.19 & 3.3 \\
\hline 2 & $\begin{array}{l}* \text { IGSO \& } \\
1 * \text { GEO }\end{array}$ & $87 \%$ & 3.95 & 3.33 & 1.85 \\
\hline 3 & $\begin{array}{l}4 * \text { IGSO \& } \\
2 * \text { GEO }\end{array}$ & $100 \%$ & 4.63 & 4.02 & 1.85 \\
\hline 4 & $\begin{array}{l}3 * \text { IGSO \& } \\
3 * \text { GEO }\end{array}$ & $100 \%$ & 3.7 & 3.29 & 1.76 \\
\hline 5 & $\begin{array}{l}2 * \text { IGSO \& } \\
4 * \text { GEO }\end{array}$ & $100 \%$ & 4.6 & 4.22 & 2.79 \\
\hline 6 & $\begin{array}{l}3 * \text { IGSO \& } \\
4 * \text { GEO }\end{array}$ & $100 \%$ & 3.57 & 3.18 & 1.67 \\
\hline 7 & $\begin{array}{ll}* \mathrm{GSO} \quad \& \\
3 * \mathrm{GEO}\end{array}$ & $100 \%$ & 3.52 & 3.09 & 1.58 \\
\hline
\end{tabular}


Table 6

Availability and Mean DOP in Kabul Station

\begin{tabular}{|l|lr|l|l|l|l|}
\hline No. & Layout & & Availability & GDOP & $\begin{array}{l}\text { PDO } \\
\text { P }\end{array}$ & HDOP \\
\hline 1 & $6 *$ IGSO & & $81 \%$ & 9.79 & 8.56 & 5.35 \\
\hline 2 & $\begin{array}{l}5 * \text { IGSO } \\
1 * \text { GEO }\end{array}$ & $\&$ & $84 \%$ & 4.24 & 3.57 & 1.97 \\
\hline 3 & $\begin{array}{l}4 * \text { IGSO } \\
2 * \text { GEO }\end{array}$ & $\&$ & $100 \%$ & 4.93 & 4.3 & 2.64 \\
\hline 4 & $\begin{array}{l}* \text { GSO } \\
3 * \text { GEO }\end{array}$ & $\&$ & $100 \%$ & 3.9 & 3.47 & 2.04 \\
\hline 5 & $\begin{array}{l}2 * \text { IGSO } \\
4 * \text { GEO }\end{array}$ & $\&$ & $100 \%$ & 6.1 & 5.71 & 4.09 \\
\hline 6 & $\begin{array}{l}3 * \text { GSO } \\
4 * \text { GEO }\end{array}$ & $\&$ & $100 \%$ & 3.76 & 3.34 & 1.91 \\
\hline 7 & $\begin{array}{llllll}* \\
3 * \text { GEO }\end{array}$ & $\&$ & $100 \%$ & 3.53 & 3.09 & 1.82 \\
\hline
\end{tabular}

The results of $3 *$ IGSO \& $3 *$ GEO Layout as a best layout in case with 6 satellites has been shown in below figures. Figure 1 is the optimum layout of this state, in this figure it is clear the results of optimization is in the borders of Omega and one of them is in the middle.

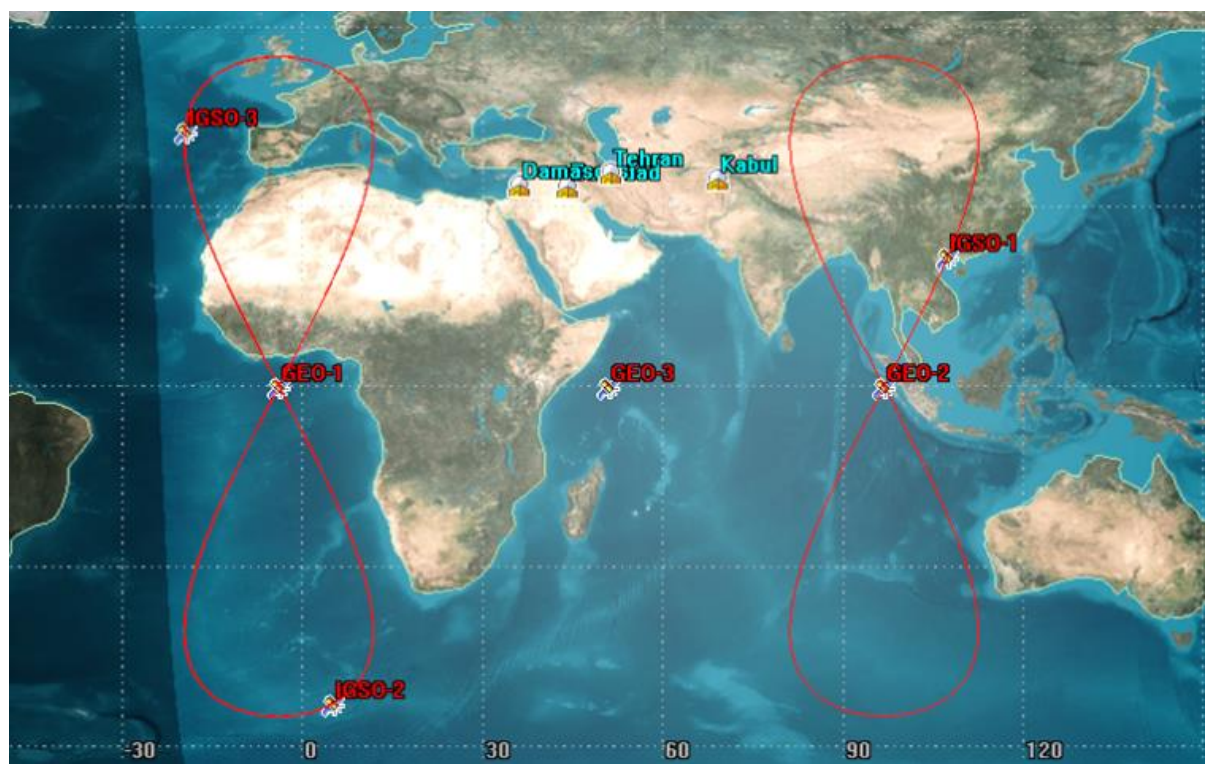

Figure 1. 3IGSO+3GEO optimum layout. 
In Figures 2 and 3, the DOP and Availability of three stations have been shown.

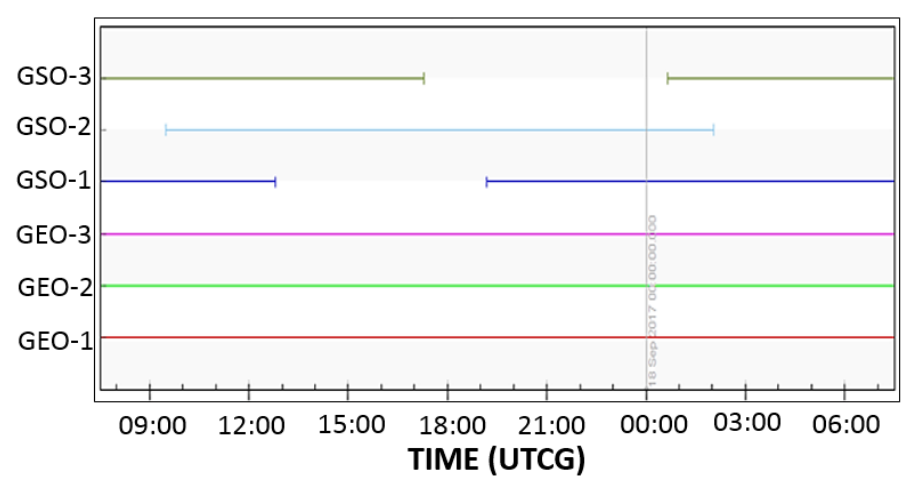

(a)

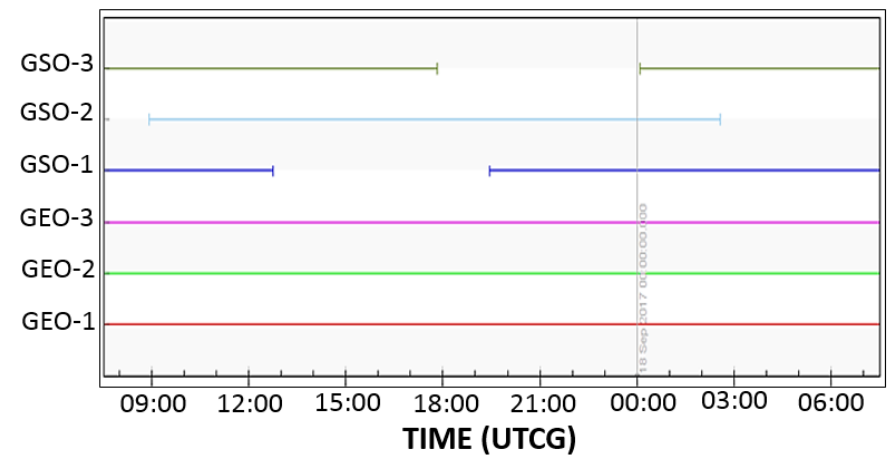

(b)

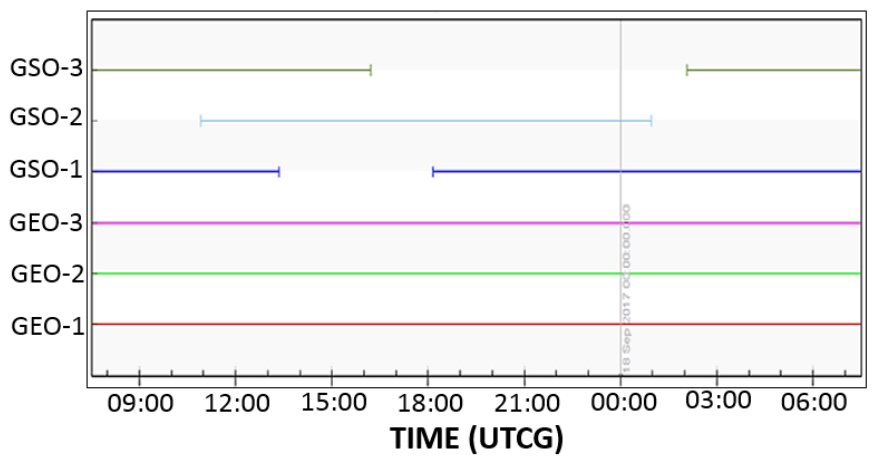

(c)

Figure 2. Availability in three stations (3IGSO+3GEO layout), (a): Tehran, (b): Beirut, (c): Kabul. 


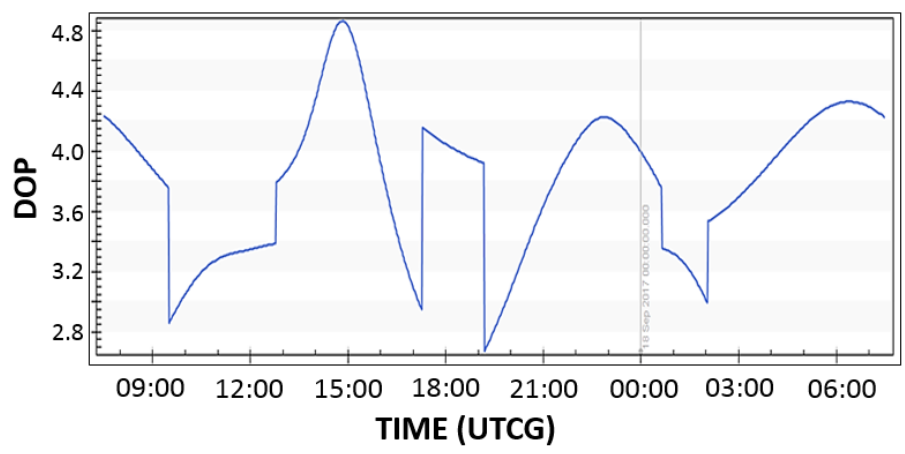

(a)

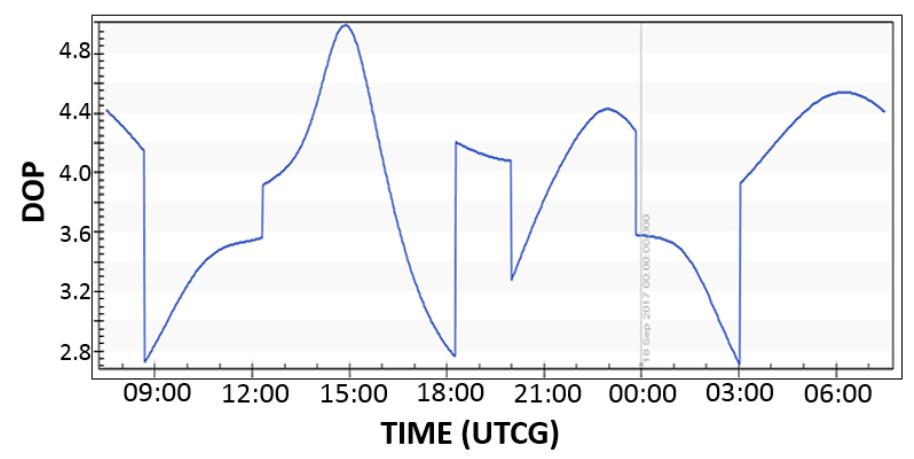

(b)

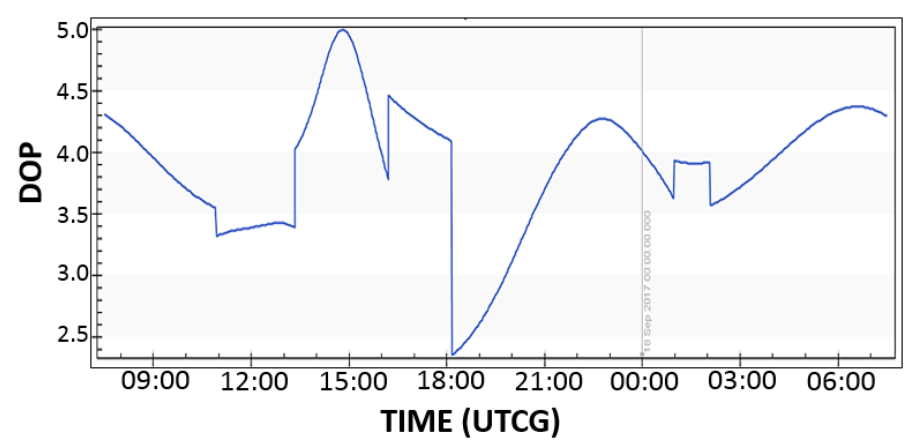

(c)

Figure 3. DOP in three stations (3IGSO+3GEO layout), (a): Tehran, (b): Beirut, (c): Kabul.

In Table 7 , the comparison of navigation constellation has been displayed. Two additional models were simulated for 8 and 10 satellites comparing the DOP values to the 6 and 7 satellite MERNSS systems. DOP values for these models as it shows the financial cost of adding more satellites is unnecessary. 
Table 7

Comparison of Navigation Constellation

\begin{tabular}{|c|c|c|c|c|c|c|c|c|}
\hline \multirow{2}{*}{$\begin{array}{l}\text { Constellation } \\
\text { name }\end{array}$} & \multirow{2}{*}{$\begin{array}{l}\text { Number } \\
\text { of } \\
\text { Satellites }\end{array}$} & \multicolumn{4}{|c|}{$\begin{array}{l}\text { Number of Satellites in each } \\
\text { orbit }\end{array}$} & \multirow{2}{*}{$\begin{array}{l}\text { GDOP } \\
\text { Average }\end{array}$} & \multirow{2}{*}{$\begin{array}{l}\text { PDOP } \\
\text { Average }\end{array}$} & \multirow{2}{*}{$\begin{array}{l}\text { HDOP } \\
\text { Average }\end{array}$} \\
\hline & & GEO & MEO & IGSO & LEO & & & \\
\hline GPS & 31 & 0 & 31 & 0 & 0 & 2.08 & 2 & 1.19 \\
\hline Galileo & 27 & 0 & 27 & 0 & 0 & $1.38-2.5$ & $1.8-2.7$ & $0.9-1.3$ \\
\hline Glonass & 24 & 0 & 24 & 0 & 0 & 2.18 & & \\
\hline Beidou & 35 & 5 & 27 & 3 & 0 & 1.31 & 1.2 & 0.65 \\
\hline IRNSS & 7 & 3 & 0 & 4 & 0 & & & $1.8-4.5$ \\
\hline CAPS & 6 & 2 & 0 & 4 & 0 & & $5.1-9$ & \\
\hline MERNSS-6 & 6 & 3 & 0 & 3 & 0 & 3.81 & 3.39 & 1.76 \\
\hline MERNSS - 7 & 7 & 3 & 0 & 4 & 0 & 3.57 & 3.13 & 1.57 \\
\hline MERNSS -8 & 8 & 4 & 0 & 4 & 0 & 3.49 & 3.04 & 1.48 \\
\hline MERNSS -10 & 10 & 5 & 0 & 5 & 0 & 3.43 & 2.98 & 1.41 \\
\hline
\end{tabular}

Genetic Algorithm (GA) is a search-based optimization technique based on the principles of Genetics and Natural Selection that in this research with MATLAB software it used to finding unknown orbital parameters for Navigation constellation. It is frequently used to find optimal or near-optimal solutions to difficult problems which otherwise would take a lifetime to solve (Gen \& Runwei, 2000). GAs have various advantages which have made them immensely popular. These include:

-Does not require any derivative information (which may not be available for many real-world problems)

-Is faster and more efficient as compared to the traditional methods

-Has very good parallel capabilities

-Optimizes both continuous and discrete functions and also multiobjective problems

-Always gets an answer to the problem, which gets better over the time

-Useful when the search space is very large and there are a large number of parameters involved

Genetic Algorithm tries to search the neighborhood for the initial solutions that you have by heuristics method to get a best or optimal solution for the problem by search this solution search space. Also, crossover and mutation operators on genetic algorithm guarantee that you can improve the initial solutions to get local and global optimum solutions (Gen \& Runwei, 2000). The parameters of evolutionary algorithms, including GA, would depend on the specific problem. So, in the general case, the best way to identify the probability would be to do a sensitivity analysis: carrying out 
multiple runs of the algorithms with different population size etc and compare the outcome.

The observed results and other similar researches which commonly suggested by existing researchers show that the optimal population size is 100 chromosomes for 300 generations. In this case accurate model parameters values are obtained in reasonable computational time. Further increase of the population size, above 100 chromosomes, does not improve the solution accuracy. Moreover, the computational time is increased significantly (Konak, Coit, \& Smith, 2006). Values of crossover and mutation probabilities depend on problem concerned. For complicated search spaces a higher value of crossover probability $(>0.5)$ will help searching at the beginning. However, with progress it should be reduced to a value near 0.1 - 0.7. Mutation probabilities normally should be kept very low (0.01 - 0.3), otherwise convergence may be delayed unnecessarily (Gen \& Runwei, 2000; Konak, Coit, \& Smith, 2006). The values of the related parameters to the algorithm are expressed below:

-Population: 100

-Generations: 300

-Crossover: 0.6

-Mutation: 0.1

-Number of algorithm runs: 280

-Fitness Function: Optimal Mean DOP (smallest value of Mean DOP)

The curve of the fitness function in terms of generations is used, which is given in Figure 4. It takes 5 minutes to run the optimization. This algorithm gets run multiple times and it chooses the same optimum constellation each time. 


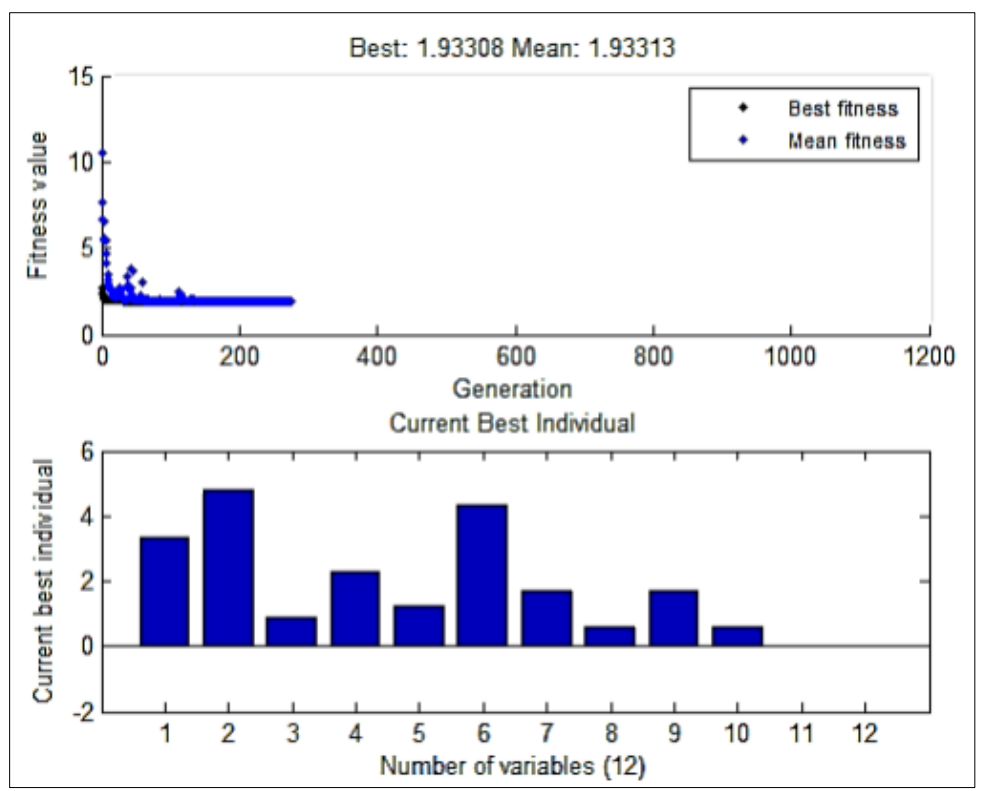

Figure 4- Fitness function diagram in the genetic algorithm.

\section{Conclusions}

The goal of this research was the optimal design of a regional navigation constellation with certain assumptions and to Service Middle Eastern countries. This design was based on the DOP parameter. The most important results are briefly outlined:

-The combination of GEO and IGSO layout is the best option for regional navigation systems

-The 3IGSO + 3GEO satellite constellation in the 6-satellite mode and the $4 \mathrm{IGSO}+3 \mathrm{GEO}$ in the state of the seven satellites have the best DOPs in the Earth stations

-At least two GEO satellites are required so that 4 Satellites can be viewed by the terrestrial observer at all times

-The minimum HDOP (Best HDOP) in the 4IGSO + 3GEO System 7 is much better than the IRNSS constellation

-It is worth mentioning that the cost of bandwidth for Geo commercial satellites depends on the amount of bandwidth purchase. It is about a few thousand dollars, so the cost constraints in this area lead us to use SIGSO satellites (Slightly Inclined end-of-life GSO-satellites) 


\section{References}

Ai, G.-X., Sheng, P.-X., Du, J.-L., Zheng, Y.-G., Cai, X.-D., . . . Li, X.-H. (2009). Barometric altimetry system as virtual constellation applied in CAPS. Science in China Series G: Physics, Mechanics and Astronomy, 52(3), 376-383.

Ai, G.-X., Shi, H.-L., Wu, H.-T., Yan, Y.-H., Bian, Y.-J., Hu, Y.-H., ... Cai, X.-D. (2008). A positioning system based on communication satellites and the Chinese Area Positioning System (CAPS). Chinese Journal of Astronomy and Astrophysics, 8(6), 611.

Angrisano, A., Pacifico, A., \& Vultaggio, M. (2008). Solving GPS gap, Coverage analysis of a super constellation made up of GPS+ $E G N O S+S-Q Z S S$. Retrieved from http://citeseerx.ist.psu.edu/viewdoc/ download? doi=10.1.1.462.1742\&rep=rep1\&type=pdf

Capderou, M. (2006). Satellites: Orbits and missions. Berlin, Germany: Springer Science \& Business Media. doi: 10.1007/b139118

Cong, L., Abidat, A. I., \& Tan, Z.-Z. (2006). Analysis and simulation of the GDOP of satellite navigation. Acta Electronica Sinica, 12, 16.

Gen, M., \& Runwei C. (2000). Genetic algorithms and engineering optimization. New York, NY: John Wiley \& Sons.

Harshada, H., Shahade, M. R., \& Badnore, D. (2015). Indian regional navigation satellite system. International Journal of Research in Science \& Engineering, 2(11), 380-384.

Konak, A., Coit, D. W., \& Smith, A. E. (2006). Multi-objective optimization using genetic algorithms: A tutorial. Reliability Engineering \& System Safety, 91(9), 992-1007.

Mao, Y., \& Sun, F. P. (2006). Global navigation satellite constellation design using Walker constellation. Journal of Zhengzhou Institute of Surveying and Mapping, 23(2), 153-156.

Montenbruck, O., Steigenberger, P., Hugentobler, U., Teunissen, P., \& Nakamura, S. (2013). Initial assessment of the COMPASS/BeiDou-2 regional navigation satellite system. GPS Solutions, 17(2), 211-222.

Renault, H. (1998). Constellation studies for future navigation system. Mission Design \& Implementation of Satellite Constellations, 163-168. Dordrecht, Netherlands: Springer.

Saikiran, B., \& Vikram, V. (2013). IRNSS architecture and applications. KIET International Journal of Communications \& Electronics, 1(3), 21-27.

Sun, F., Liu, S., Zhu, X., \& Men, B. (2012). Research and progress of Beidou satellite navigation system. Science China Information Sciences, 55(12), 2899-2907.

Ulybyshev, Y. (2008). Satellite constellation design for complex coverage. Journal of Spacecraft and Rockets, 45(4), 843-849. 